\title{
Delayed development of phonological constancy in toddlers at family risk for dyslexia
}

$$
\text { Marina Kalashnikova }{ }^{1,2} \text {, Usha Goswami }{ }^{3} \text {, Denis Burnham }{ }^{2}
$$

${ }^{1}$ BCBL. Basque Center on Cognition, Brain and Language, Donostia, Spain

${ }^{2}$ The MARCS Institute for Brain, Behaviour and Development, Western Sydney University, Penrith, Australia

${ }^{3}$ Centre for Neuroscience in Education, University of Cambridge, Cambridge, UK

Corresponding author: Marina Kalashnikova, BCBL. Basque Center on Cognition, Brain and Language, Mikeletegi Pasealekua, 69, Donostia, Gipuzkoa, 20009, Spain; t: +34 943309300 (ext: 234), m.kalashnikova@westernsydney.edu.au

Acknowledgements: This research was supported by the Australian Research Council grant DP110105123, 'The Seeds of Literacy', to the $3^{\text {rd }}$ and $2^{\text {nd }}$ authors. We thank Maria CristouErgos, Scott O’Loughlin, and Hana Zjakic for their assistance with participant recruitment, data collection, and data analyses. We also thank all the infants and their parents for their valuable time and interest in this research. 


\title{
PHONOLOGICAL CONSTANCY IN INFANTS AT-RISK FOR DYSLEXIA
}

\author{
Abstract \\ Phonological constancy refers to infants' ability to disregard variations in the phonetic \\ realisation of speech sounds that do not indicate lexical contrast, e.g., when listening to \\ accented speech. In typically-developing infants, this ability develops between 15- and 19- \\ months of age, coinciding with the consolidation of infants' native phonological competence \\ and vocabulary growth. Here we investigated the developmental time course of phonological \\ constancy in infants at family risk for developmental dyslexia, using a longitudinal design. \\ Developmental dyslexia is a disorder affecting the acquisition of reading and spelling skills, \\ and it also affects early auditory processing, speech perception, and lexical acquisition. \\ Infants at-risk and not at-risk for dyslexia, based on a family history of dyslexia, participated \\ when they were 15-, 19-, and 26-months of age. Phonological constancy was indexed by \\ comparing at-risk and not at-risk infants' ability to recognise familiar words in two \\ preferential looking tasks: (1) a task using words presented in their native accent, and (2) a \\ task using words presented in a non-native accent. We expected a delay in phonological \\ constancy for the at-risk infants. As predicted, in the non-native accent task, not at-risk \\ infants recognised familiar words by 19 months, but at-risk infants did not. The control \\ infants thus exhibited phonological constancy. By 26 months, at-risk toddlers did show \\ successful word recognition in the native accent task. However, for the non-native accent task \\ at 26 months, neither at-risk nor control infants showed familiar word recognition. These \\ findings are discussed in terms of the impact of family risk for dyslexia on toddlers' \\ consolidation of early phonological and lexical skills.
}


PHONOLOGICAL CONSTANCY IN INFANTS AT-RISK FOR DYSLEXIA

\section{Introduction}

Approximately $7-10 \%$ of children worldwide do not acquire age-appropriate literacy skills despite having normal intelligence and full access to educational opportunities. These children are affected by dyslexia, a neurodevelopmental disorder of reading and spelling skills (Snowling, 2000). Even though dyslexia is commonly defined as a reading disorder, its effects are also observed in more general language abilities. Specifically, individuals with dyslexia exhibit persistent difficulties in acquiring phonological skills (Snowling, 2000). This is manifested in lower performance in measures of phonological awareness, phonological short term memory, and measures of lexical encoding and retrieval compared to both same-age controls and frequently also younger reading-level matched controls. At the cognitive level, this 'phonological deficit' is considered to be a cause of the reading difficulties associated with dyslexia (Ziegler \& Goswami, 2005). More recent evidence suggests that the phonological and associated linguistic deficits in dyslexia may be rooted in atypical sensory processing, particularly atypical auditory processing (Goswami, 2015; Moll, Loff, \& Snowling, 2013; Ramus, 2003; Ramus, Marshall, Rosen \& Van Der Lely, 2013; Swan \& Goswami, 1997; although see Zoccolotti \& Friedmann, 2010). Nevertheless, research on the development of general auditory and language abilities in pre-reading infants and children who are at-risk for developing dyslexia remains scarce. Tests of sensory-based theories of dyslexia in these populations are particularly valuable for ascertaining causality as, once literacy tuition begins, there are reciprocal developmental relationships between phonological skills and literacy skills (Goswami, 2015).

Longitudinal studies of infants at family risk for dyslexia provide a particularly strong test of sensory hypotheses (Guttorm et al., 2005; van Zuijen, Plakas, Maassen, Maurits, \& van der Leij, 2013). We have been conducting such a study with a cohort of 
PHONOLOGICAL CONSTANCY IN INFANTS AT-RISK FOR DYSLEXIA

Australian English participants (Kalashnikova, Goswami \& Burnham, 2018). In the current report, we focus on early phonological competence; specifically, the development of phonological constancy, and its effects on the quality of early lexical representations in infants and toddlers who are and are not at family-risk for dyslexia.

While dyslexia is typically manifested in 7 to $10 \%$ of the general population, approximately 35 to $65 \%$ children who are at family risk for dyslexia (by virtue of having at least one dyslexic parent) are later diagnosed with this disorder (Fisher \& DeFries, 2002). Longitudinal studies that assess the early auditory processing and language skills in at-risk children during their early years allow for retrospective identification of the early behavioural or neural predictors of reading disability (i.e., to discriminate those at-risk children who will and will not later be diagnosed as dyslexic) (e.g., Lyytinen et al., 2004; Pennington \& Lefly, 2001; Snowling \& Melby-Lervag, 2016; Van Bergen et al., 2011). Nevertheless, there is also evidence that group differences can be observed even in cross-sectional analyses comparing at-risk and control infants. This suggests that some markers of dyslexia are present regardless of whether the child goes on to exhibit the severe problems with reading and spelling that would result in a formal diagnosis of dyslexia. For instance, electroencephalography (EEG) recordings of infants' responses (from birth to six months of age) to changes in acoustic features of speech stimuli such as pitch (F0), vowel length, and stop consonant voice onset time (VOT) have shown significant deficits in change detection in at-risk infants compared to controls as well as hemispheric differences in the cortical distribution of their responses (Guttorm et al., 2005; Guttorm, Leppänen, Hamalainen, Eklund, \& Lyytinen, 2010; Leppänen et al., 2010; Richardson, Leppänen, Leiwo, \& Lyytinen, 2003; van Zuijen et al., 2013). Another acoustic factor investigated in relation to dyslexia is amplitude envelope 'rise time' discrimination (Goswami et al., 2002). 


\section{PHONOLOGICAL CONSTANCY IN INFANTS AT-RISK FOR DYSLEXIA}

Rise time is the time period from the onset of an amplitude envelope to its point of maximum amplitude, and it plays a central role in speech processing. Accurate perception of the speech amplitude envelope is important for speech intelligibility (Shannon et al., 1995), and the rise times of syllable-related modulations in the envelope play a core role in neural speech encoding (Doelling, Arnal, Ghitza, \& Poeppel, 2014). Rise time discrimination is associated with phonological development and dyslexia across languages (Goswami, 2011, 2015, 2018). Deficits in rise time perception have been documented in pre-school children at-risk for dyslexia (Law, Wouters \& Ghesquiere, 2017; Plakas, van Zuijen, van Leeuwen, Thomson, \& van der Leij, 2013), as well as in samples of dyslexic school-aged children, using both psychoacoustic and neural measures (Beattie \& Manis, 2015; Hamalainen et al., 2008; Goswami, Fosker, Huss, Mead, \& Szucs, 2011; Goswami, Wang, et al., 2011; Poelmans et al., 2011; Stefanics et al., 2011; Suranyi et al., 2009; see Hamalainen, Salminen, \& Leppänen, 2013 for a comprehensive review). Recently we have shown, in the same longitudinal sample included in the current study, that there are significant impairments in amplitude envelope rise time discrimination even at 10 months of age for those infants at family risk of dyslexia (Kalashnikova et al., 2018). Given that these difficulties in auditory processing are already detected during at-risk children's first year of life, they are likely to have implications for early neural speech encoding

processes and for the development of speech perception (Di Liberto et al., 2018; Power, Mead, Barnes, \& Goswami, 2012, 2013) and lexical skills. The latter have not yet been studied and are the focus of this study.

It is well documented that infants come to the world equipped with universal speech perception skills for both phonetic distinctions that are and are not phonemic in their native language (Werker \& Hensch, 2015; Werker \& Tees, 2005). As young 


\section{PHONOLOGICAL CONSTANCY IN INFANTS AT-RISK FOR DYSLEXIA}

infants' native language exposure increases over age, their speech perception becomes more language-specific. This process, known as perceptual reorganisation, is characterised by maintained or increased discrimination performance for native phonetic contrasts and a simultaneous decrease in discrimination performance for nonnative contrasts (Kuhl, 2004). Perceptual reorganisation for vowels and lexical tones is evident as early as four to six months (Mattock, Molnar, Polka, \& Burnham, 2008; Tsuji \& Cristia, 2014), and it continues from approximately seven until 11 to 12 months of age for consonants (Werker \& Curtin, 2005; Werker \& Tees, 2005). Perceptual reorganisation is an important milestone in early language acquisition; it facilitates infants' discrimination of speech contrasts that signify changes in word meanings in their language, thus laying the foundation for the development of lexical abilities (Curtin, Byers-Heinlein, \& Werker, 2011; Gogate, 2010; Yoshida, Fennell, Swingley, \& Werker, 2009).

By their first birthday, infants already possess a sizeable receptive vocabulary (Fenson et al., 1994). Importantly, the phonological details of these early words are already stored in the lexicon. For instance, when infants from 11 months of age are presented with two visual referents and hear the label of one of them, they prefer to look at the correct referent. However, if they hear a mispronounced version of the label, this preference is either diminished or absent (Swingley, 2005; Swingley \& Aslin, 2000, 2007). Of course, not all changes to the phonetic realisation of a word form signal a change in its meaning. Thus, there is a need for the complementary skill known as phonological constancy, which is the ability to disregard phonetic variations that do not denote a phonological contrast (Best, 1994). Phonological constancy is not trivial. Phonetic variation is ubiquitous in natural speech, occurring as a result of regional accents and other idiosyncratic differences in speech production. The inability to 
PHONOLOGICAL CONSTANCY IN INFANTS AT-RISK FOR DYSLEXIA

contend with this natural variation would lead children to discard false mispronunciations of words in their language, consequently impairing learning of new lexical items and potentially leading to communication breakdowns.

Best and colleagues (Best, Tyler, Gooding, Orlando, \& Quann, 2009) demonstrated that phonological constancy emerges between the ages of 15- and 19months in typically-developing infants, which coincides with the period when infants' vocabulary size undergoes significant growth (Fenson et al., 1994; Nazzi \& Bertoncini, 2003). Best et al. (2009) assessed phonological constancy by measuring infants' ability to recognise familiar words when presented in their native accent of English versus an accent that they had never heard before, Jamaican English. At 15 months, infants only recognised words when they were presented in their native accent, but at 19 months, word recognition was successful in the native and non-native accents. Nevertheless, more recent research indicates that the developmental shift detected by Best et al. around 19 months represents the onset of this ability rather than its attainment since infants' ability to contend with phonetic variability continues to develop until their third year of life (Cristia et al., 2012; Schmale, Cristia, \& Seidl, 2012; Schmale, Cristia, Seidl, \& Johnson, 2010; Van Heugten, Krieger, \& Johnson, 2015).

The ability of infants at-risk for dyslexia to cope with phonological variation is currently unknown. However, there is reason to predict a delay in the onset of such phonological constancy in this population. Specifically, dyslexic children and adults have been shown to retain sensitivity to non-native speech contrasts that are not part of their native language phonemic inventory (Noordenbos \& Serniclaes, 2015). That is, in comparison to individuals not affected by dyslexia, they show persistent differences in categorical perception tasks that require the identification of tokens that belong to a single phonemic category or discrimination between tokens that belong to different 


\section{PHONOLOGICAL CONSTANCY IN INFANTS AT-RISK FOR DYSLEXIA}

phoneme categories (Bogliotti, Serniclaes, Messaoud-galusi, \& Sprenger-charolles, 2008; Collet et al., 2012; Noordenbos et al., 2012). Neural measures also suggest that children with dyslexia do not generalise across different tokens of the same syllable (Chandrasekaran, Hornickel, Skoe, Nicol, \& Kraus, 2009). In addition, early differences in speech perception would be expected on the basis of impaired discrimination of amplitude envelope rise times, which is already present in at-risk infants before the age of one year (Kalashnikova et al., 2018). That is, impaired perception of the slowlyvarying speech amplitude envelope is proposed to be compensated for by increased reliance on rapidly-changing speech information (corresponding to phonetic units). This compensation would result in perceptual discrimination of allophonic variations beyond infancy (Goswami, 2011) and/or neural 'over-sampling' of rapidly-changing speech information (Lehongre, Ramus, Villiermet, Schwartz, \& Giraud, 2011).

In light of these perceptual differences, it can be expected that the specificity and robustness of early lexical representations is also affected in individuals with dyslexia. For example, van Alphen et al. (2004) assessed mispronunciation detection in five-yearold children at-risk for dyslexia, and demonstrated that a deficit was already present in comparison to same-aged controls. In their task, children heard mispronounced versions of familiar words and were asked to indicate whether they were said wrong. Even though this result could not be due to differences in reading ability as the children had not begun reading instruction, arguably this type of behavioural task still requires a degree of phonological awareness (i.e., the requirement of making a judgment about a word form; Boada \& Pennington, 2006), which may have disadvantaged the children atrisk for dyslexia.

The current study investigated phonological constancy skills in infants at-risk and not at-risk for dyslexia, who were tested longitudinally at 15, 19, and 26 months of 
PHONOLOGICAL CONSTANCY IN INFANTS AT-RISK FOR DYSLEXIA

age. Following Best et al. (2009), infants were presented with familiar and unfamiliar words in their native accent and in a non-native accent. It was expected that infants would generally show a preference for familiar words, as indexed by longer listening times. If infants recognised words produced in a novel accent, then they were expected to listen longer to familiar words regardless of the accent of presentation. However, if infants did not recognise familiar words produced in a novel accent, then a preference for familiar words was expected only when they heard their native accent. According to Best et al., a preference for native accent familiar words was anticipated for typicallydeveloping 15-month-olds, whereas a preference for both native and non-native accent familiar words was anticipated for typically-developing 19- and 26-month-olds.

Because a sub-sample of the participating infants who were at-risk for dyslexia had already demonstrated deficits in early auditory abilities (Kalashnikova et al., 2018), we predicted a delay in achieving phonological constancy for the at-risk group. It is possible that the at-risk infants would underperform compared to controls at all ages and in all conditions, showing a general delay in word recognition. Alternatively, and more likely, the ability of at-risk infants to recognise words was predicted to increase with age in the native accent condition, but at a slower pace than controls. In the nonnative accent condition, controls' preference is expected to begin around 19 months, but no preference was expected for at-risk children at any age. This prediction was because prolonged maintenance of non-native perception would mean that all words in a nonnative accent would be perceived as unfamiliar. Specifically for the current preferential listening tasks, we expected a four-way interaction between word familiarity, accent, group and age, driven by different interactions of familiar/novel word by native/nonnative accent by age for the at-risk and for the not at-risk infants, as follows: 
PHONOLOGICAL CONSTANCY IN INFANTS AT-RISK FOR DYSLEXIA

(i) controls were expected to prefer familiar words only in their native accent at 15 months, but in both the native and non-native accents at 19 and 26 months, whereas

(ii) at-risk infants were expected to show preference for familiar words only in their native accent at 15 and 19 months, and possibly an emerging familiar word preference in the non-native accent by 26 months or possibly no familiar word preference in non-native accents at any age.

\section{Method}

\subsection{Participants}

Forty-three infants took part in this study when they were 15, 19, and 26 months of age. All infants were acquiring Australian English in a monolingual environment. The infants were selected from the 'Seeds of Literacy' five-year longitudinal project based on their availability to complete the experimental sessions. An additional 27 infants also participated, but were excluded from the final analyses due to exposure to other languages (2) or to varieties of English other than Australian English (5), risk for developmental disorders other than dyslexia (1), and due to failure to contribute analysable data (19). The sample size was modeled based on the previous study by Best et al. (2009; $n=20)$, and it was determined by infants' availability to complete the longitudinal testing schedule. This study was approved by the Western Sydney University Human Research Ethics Committee (approval number H9142).

Twenty-one infants (11 female) were assigned to the at-risk for dyslexia (ARDx) group by virtue of having one parent diagnosed with dyslexia. Twenty-two infants (14 female) were assigned to the control (CTR) group and were not at risk for any developmental disorders. In order to confirm infants' group assignment and parental diagnosis, parents of all infants completed a comprehensive battery of reading, literacy- 


\section{PHONOLOGICAL CONSTANCY IN INFANTS AT-RISK FOR DYSLEXIA}

related skills, and general cognitive tasks. In order to be assigned to the AR group, one of the child's parents was required to score 1.5SD below the mean in (1) a measure of word and non-word reading and a measure of phonological awareness, (2) indicate history of experiencing reading difficulties in childhood, and (3) have average nonverbal IQ. In order to be assigned to the NAR group, both parents were required to obtain scores within $.5 \mathrm{SD}$ of the mean on all the screening tests. In addition, maternal education was assessed as a proxy for the families' socio-economic status. Mothers' education ranged from a high school diploma to a doctorate. The median education level for the two groups was a university degree, and this did not differ between groups, Kolmogorov-Smirnov $Z=.333, p=1$.

In order to be included in the final sample for the longitudinal analyses, infants were required to complete the word recognition task and contribute analysable data on at least two of the three visits. Among the infants in the final sample, 5 were missing data at 15 months (3 CTR, 2 ARDx), 1 at 19 months (1 CTR), and 5 at 26 months (4 CTR and 1 ARDx). Infant age between the two groups was equivalent at the 15- (CTR $M=65.98$ weeks, $S D=1.69 ;$ ARDx $M=65.38$ weeks, $S D=.78, t(36)=1.402, p=$ $.170, d=.467), 19-(\mathrm{CTR} M=83.12$ weeks, $S D=1.05$; ARDx $M=83.42$ weeks, $S D=$ $.78, t(36)=.789, p=.435, d=.263)$, and 26-months lab visits (CTR $M=113.57$ weeks, $S D=1.26$; ARDx $M=113.01$ weeks, $S D=.86, t(36)=1.627, p=.113, d=.542)$. When the infants were 24 months of age, they also completed the Bayley Scales of Infant and Toddler Development (Soleimani \& Azari, 2014) as a comprehensive measure of general cognitive development, and the scaled scores did not differ between the groups $(M \mathrm{CTR}=12.3, S D=2.69, M \mathrm{ARDx}=12.76, S D=2.98), t(39)=.519, p=$ $.606, d=.166$, suggesting that infants at-risk for dyslexia did not have an additional cognitive delay. 
PHONOLOGICAL CONSTANCY IN INFANTS AT-RISK FOR DYSLEXIA

\subsection{Materials and apparatus}

The auditory stimuli from Best et al. (2009) were used. These consisted of two sets of audio recordings of 48 words. The first set was produced by a native male speaker of Australian English (AusE) and the second set by a male native speaker of Jamaican English (JamE). JamE was completely novel to all infants who participated in this study, and this variety of English differs significantly from AusE in its phonetic realisations of vowels, consonants, and prosody (Patrick, 1999; Wassink, 2006). Half of the words ( 24 words) were high frequency and early age-of-acquisition words. These words were used for the familiar condition as they were expected to be familiar to infants around 15 months of age (Best et al., 2009). The other half (24) were used in the unfamiliar condition as they were low frequency and late age-of-acquisition words. The 24 words recorded in each accent and familiarity condition were concatenated into 16 lists in which the words appeared in different randomised orders. Each child completed 8 experimental trials ( 4 familiar and 4 unfamiliar), and the testing software randomly selected a different list for every trial. The visual stimuli consisted of a colourful checkerboard presented on the screen to maintain children's attention to the auditory stimuli. Visual stimuli were presented on a 22 in monitor, and auditory stimuli were presented over loudspeakers at a volume comfortable for the children.

\subsection{Procedure}

Infants sat on their parent's lap approximately $60 \mathrm{~cm}$ away from the computer monitor inside an infant laboratory testing room. Parents listened to masking sounds over noise-cancelling headphones and were instructed to remain silent and to avoid pointing to the screen. A CCTV camera hidden below the screen was used to record the child's gaze direction. An experimenter sat in an adjoining room, observed the child's 
PHONOLOGICAL CONSTANCY IN INFANTS AT-RISK FOR DYSLEXIA

behaviour on a computer monitor, and recorded when the child looked to or away from the screen in real time by pressing the spacebar on a computer keyboard.

Each child completed two preferential listening tasks presented consecutively in a single experimental session. In one task, all stimuli were presented in AusE and in the other, in JamE. The structure of the tasks was identical. Each task included 4 familiar and 4 unfamiliar trials presented in alternating order. At the start of the task, infants were presented with an attention-getter stimulus (a circular shape expanding and retracting on the screen in silence) until they fixated the screen for a period of two seconds. The same stimulus was presented to re-direct infants' attention to the screen between test trials. Next, infants were presented with four familiar word trials and four unfamiliar word trials in alternating order. During the trials, infants saw the image of a colourful checkerboard on the screen and listened to the words. The stimuli only played while the child looked to the screen. The trial was terminated when the child looked away for a period of two seconds or if the maximum trial duration of 30 seconds was reached. In order to maintain children's attention during the two tasks, the colour of the checkerboard image was different for Tasks 1 and 2. The order of the accent presentation, the familiar and unfamiliar stimuli, and the colour of the checkerboard were all counterbalanced between participants and across ages for each participant.

\section{Results}

Infants' looking duration in milliseconds during each experimental trial were calculated for analyses. Mixed effects models were used to account for the repeated measures of age and condition as well as to analyse infants' performance in each trial of the task. The Linear Mixed Effects (LME) models were conducted using the lme4 package in R (Bates, 2005). The initial model (Model - Longitudinal) included infants' performance between risk groups, ages, accents, and test conditions of familiarity, and it 
PHONOLOGICAL CONSTANCY IN INFANTS AT-RISK FOR DYSLEXIA

was specified as follows: with the independent variables Group (ARDx, CTR), Accent (AusE, JamE), Familiarity (Familiar, Unfamiliar), Age (15, 19, and 26 months), and their 4-way interaction, with looking time as the dependent variable. Next, to elucidate the predicted interactions, three separate models were constructed, one at each of the three ages $(15,19$, and 26 months), and they were specified as follows: with the independent variables Group (ARDx, CTR), Accent (AusE, JamE), Familiarity (Familiar, Unfamiliar), and their 3-way interaction, and looking time as the dependent variable. In all of the models, the maximum random effects structure was planned, which involved the specification of random intercepts for participant and experimental trial and random slopes for the relevant independent variables. In the cases where the models failed to converge, random slopes were removed. In all models, significant main effects and interactions were followed by pairwise comparisons using the lmerTest and Diffsmeans packages in R (Kuznetsova, Brockhoff, \& Christensen, 2015). Detailed output of all models is presented in Appendix B.
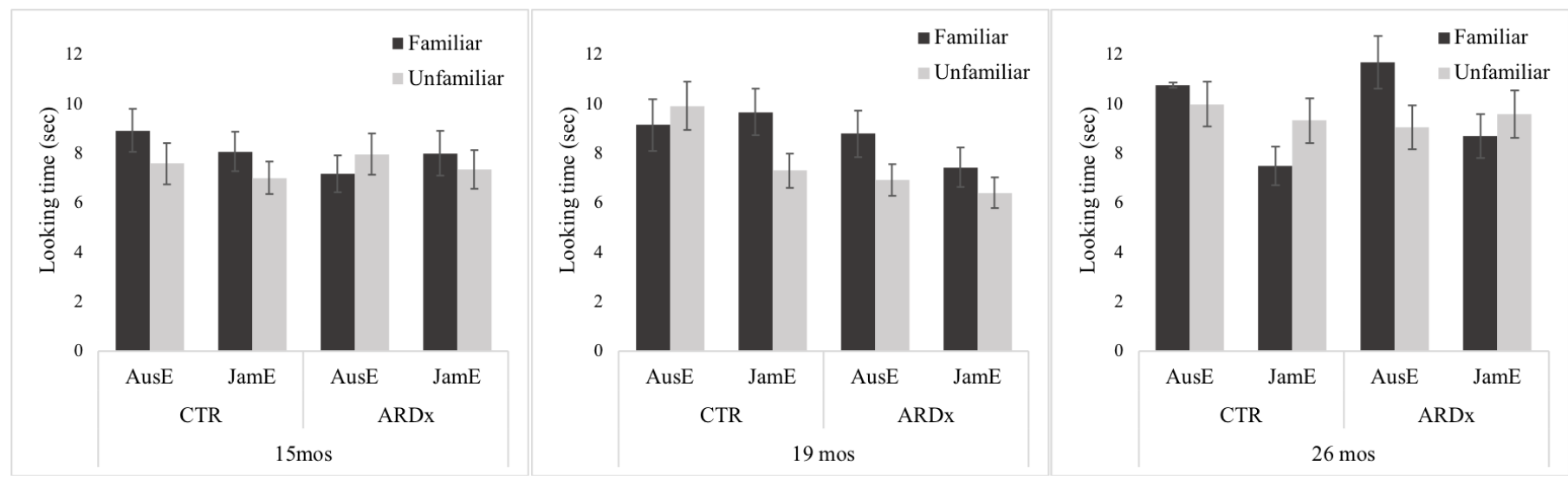

Figure 1. Control (CTR) and at-risk (ARDx) infants' mean looking duration in response to familiar and unfamiliar words presented in Australian English (AusE) and Jamaican English (JamE) at 15 (left), 19 (center), and 26 (right) months (error bars represent SEM).

3.1 Longitudinal analysis of ARDx and CTR performance at 15, 19, and 26 months 
For the first analysis, an LME model (Model - Longitudinal) was constructed with the independent variables Group (ARDx, CTR), Accent (AusE, JamE), Familiarity (Familiar, Unfamiliar), and Age (15, 19, and 26 months), and their 4-way interaction, looking time as the dependent variable, and random intercepts for participant, and trial number. Table 1 provides a summary of the model. As can be seen, there were significant main effects of Accent, Familiarity, and Age. Infants' listened longer to AusE $(M=9.01, S E=.27)$ than $\operatorname{JamE}(M=8.02, S E=.24)$ and to familiar $(M=8.18$, $S E=.24)$ than unfamiliar words $(M=8.85, S E=.27)$. Infants also increased their overall looking times over age $(M 15 \mathrm{mos}=7.76, S E=.29 ; M 19 \mathrm{mos}=8.18, S E=.30$; $M 26 \operatorname{mos}=9.59, S E=.34)$. The model also yielded significant interactions of Group $\times$ Age, and Accent $\times$ Familiarity $\times$ Age. In order to interpret the two- and the three-way interactions, LME models were conducted for each of the three ages following our prediction that performance between the CTR and ARDx infants would differ for each age group.

\begin{tabular}{lrrr}
\hline & \multicolumn{3}{c}{$d f$} \\
\hline Group & 0.123 & $1,40.88$ & .728 \\
Accent & 11.039 & $1,1463.02$ & .001 \\
Familiarity & 5.078 & $1,1659.77$ & .024 \\
Age & 7.842 & $2,1487.68$ & .001 \\
Group $\times$ Accent & 0.535 & $1,1462.93$ & .465 \\
Group $\times$ Familiarity & 0.086 & $1,1661.1$ & .769 \\
Accent $\times$ Familiarity & 0.546 & $1,1467.02$ & .460 \\
Group $\times$ Age & 4.037 & $2,1488.51$ & .018 \\
Accent $\times$ Age & 1.799 & $2,1462.99$ & .166 \\
Familiarity $\times$ Age & 0.388 & $2,860.9$ & .678 \\
Group $\times$ Accent $\times$ Condition & 0.798 & $1,1466.58$ & .372 \\
Group $\times$ Accent $\times$ Age & 0.114 & $2,1462.94$ & .892 \\
Group $\times$ Familiarity $\times$ Age & 1.430 & $2,859.1$ & .240 \\
Accent $\times$ Familiarity $\times$ Age & 4.496 & $2,1466.9$ & .011 \\
Group $\times$ Accent $\times$ Familiarity $\times$ & 1.821 & $2,1466.61$ & .162 \\
Age & & & \\
\hline
\end{tabular}

Table 1. Summary of Model - Longitudinal analyzing infants' performance at 15, 19, and 26-months $(N=43)$. 
PHONOLOGICAL CONSTANCY IN INFANTS AT-RISK FOR DYSLEXIA

\subsection{ARDx and CTR group comparison at 15 months}

For the 15-month-old data, an LME model (Model 2 - 15 mos) was constructed with the independent variables Group (ARDx, CTR), Accent (AusE, JamE), Familiarity (Familiar, Unfamiliar), and their interactions, with looking time as the dependent variable, and random intercepts for participant and trial number (see summary in Table 2). The model yielded no main effects or interactions. As can be seen in Figure 1 (left panel), 15-month-old infants did not show differences in looking time when they listened to familiar or unfamiliar words in AusE or JamE, and there were no significant performance differences between the ARDx and CTR groups.

\begin{tabular}{lrrrr}
\hline & $F$ & \multicolumn{2}{c}{$d f$} \\
\hline Accent & 0.449 & 1,292 & .503 \\
Familiarity & 0.992 & 1,257 & .320 \\
Group & 0.074 & 1,35 & .787 \\
Accent $\times$ Familiarity & 0.372 & 1,292 & .542 \\
Accent $\times$ Group & 0.749 & 1,292 & .387 \\
Familiarity $\times$ Group & 1.175 & 1,257 & .279 \\
Accent $\times$ Familiarity $\times$ & 0.837 & 1,292 & .361 \\
Group & & & \\
\hline
\end{tabular}

Table 2. Summary of Model 2 - 15mos analysing ARDx and CTR infants' performance at 15 months $(N=35)$.

\subsection{ARDx and CTR group comparison at 19 months}

An identical LME model to that for 15-month-old data was constructed to analyse infants' performance at 19 months (Model - 19 mos; see summary in Table 3). In this case, there was a main effect of Accent and a marginal effect of Familiarity. All infants looked longer in response to AusE $(M=8.67, S E=.46)$ than JamE words $(M=$ $7.68, S E=.39)$, and in response to familiar $(M=8.74, S E=.47)$ than unfamiliar words $(M=7.61, S E=.38)$. These main effects were also qualified by an Accent $\times$ Familiarity $\times$ Group interaction. To inform this three-way interaction, infants' looking durations were assessed for each risk group and each accent individually. Paired-samples $t$-tests 


\section{PHONOLOGICAL CONSTANCY IN INFANTS AT-RISK FOR DYSLEXIA}

comparing looking times in familiar and unfamiliar trials showed that for CTR infants, there was no familiarity preference when words were presented in AusE, $t(150)=.539$, $p=.59(95 \% \mathrm{CI}[-2.06,3.62])$, but there was a preference for familiar words in JamE, $t(150)=2.015, p=.045(95 \%$ CI $[7.30,9.67])$. For ARDx infants, there was no familiarity preference when words were presented in either AusE, $t(158)=1.641, p=$ $.103(95 \%$ CI $[-4.13, .38])$ or in JamE, $t(158)=1.023, p=.308(95 \%$ CI $[-3.01, .96])$.

Hence, only CTR infants showed evidence of familiar word preference and only when the words were presented in JamE (Figure 1, center panel).

\begin{tabular}{lrrr}
\hline & $F$ & \multicolumn{2}{c}{$p$} \\
\hline Accent & 4.234 & 1,308 & .040 \\
Familiarity & 3.091 & 1,271 & .080 \\
Group & 2.736 & 1,37 & .107 \\
Accent $\times$ Familiarity & 1.284 & 1,308 & .258 \\
Accent $\times$ Group & 0.011 & 1,308 & .917 \\
Accent $\times$ Group & 0.259 & 1,271 & .611 \\
Accent $\times$ Familiarity $\times$ & 4.265 & 1,308 & .040 \\
Group & & & \\
\hline
\end{tabular}

Table 3. Summary of Model - 19 mos analysing ARDx and CTR infants' performance at 19 months $(N=35)$.

\subsection{ARDx and CTR group comparison at 26 months}

A summary of the Model -26 mos is shown in Table 4. In this case, the model yielded a main effect of Accent. As was the case at 19-months, all infants showed a preference for AusE $(M=10.37, S E=.49)$ over JamE $(M=8.78, S E=.45)$. This was qualified by an Accent $\times$ Familiarity interaction. Planned multiple comparisons showed that infants listened longer to AusE familiar than AusE unfamiliar words, $\beta=-1.77, S E$ $=.85, z=-2.092, p=.037$, but they did not listen longer to JamE familiar than JamE unfamiliar words, $\beta=1.34, S E=.87, z=1.542, p=.123$. Thus, at 26 months all infants showed a preference for familiar over unfamiliar words in their native accent, but there was no such preference for familiar words in a novel accent (Figure 1, left panel). 


\begin{tabular}{lrrrr}
\hline & $F$ & \multicolumn{1}{c}{$d f$} & \\
\hline Accent & 8.984 & $1,303.129$ & .003 \\
Familiarity & 0.172 & $1,263.914$ & .679 \\
Group & 0.072 & $1,35.989$ & .790 \\
Accent $\times$ Familiarity & 6.694 & $1,314.121$ & .010 \\
Accent $\times$ Group & 0.076 & $1,302.94$ & .784 \\
Familiarity $\times$ Group & 1.283 & $1,264.211$ & .258 \\
Accent $\times$ Familiarity $\times$ & 0.144 & $1,312.78$ & .705 \\
Group & & & \\
\hline
\end{tabular}

Table 4. Summary of Model - 26 mos analysing ARDx and CTR infants' performance at 26 months $(N=37)$.

\section{Discussion}

This longitudinal study assessed the development of phonological constancy skills in infants at-risk and not at-risk for developmental dyslexia. The results show that infants' early lexical representations and their ability to contend with phonetic variation present in accented speech undergo a developmental change during their second and third years of life. At 15-months, infants in the control and the at-risk groups showed no preference for familiar words in either their native or a non-native accent. At 19months, while there was a general preference for familiar over unfamiliar words in both accents and groups, the only specific comparison that was significant was for the control infants' preference for familiar words produced in the non-native accent. At 26months, a further shift in performance was observed for the two groups: both control and at-risk groups showed an overall preference to listening to their native accent, and a preference for familiar words in their native accent, but neither group showed a preference for familiar words in the non-native accent. Compared to their performance at 19 months, control infants at 26 months therefore no longer demonstrated phonological constancy in our preferential looking procedure.

Phonological constancy has been shown to emerge between 15 and 19 months in typically developing infants (Best et al., 2009) using the paradigm used here. In the 
PHONOLOGICAL CONSTANCY IN INFANTS AT-RISK FOR DYSLEXIA

current study, we replicated the original finding by Best et al. The 19-month-old infants in the control group also showed a preference for listening to familiar over unfamiliar words that were presented in an accent that they had never heard before, indicating phonological constancy. By contrast, 19-month-old infants at-risk for dyslexia only showed a listening preference to familiar words in their native accent, so they did not show phonological constancy. The developmental shift to word recognition in nonnative accents is typically attributed to the consolidation of native phonological competence and growing vocabulary size, two abilities that have been shown to be impaired in infants at-risk for developmental dyslexia.

Given that this study involved infants at-risk for dyslexia, but not yet diagnosed as such, our results suggest that over and above early deficits found in such at-risk infants - in auditory processing (Guttorm et al., 2005; Kalashnikova et al., 2018; Leppänen et al., 2010) and categorical speech perception (Noordenbos \& Serniclaes, 2015 ) - there are also deficits in the development of lexical representations between 15 and 26 months. Nineteen-month-old infants at-risk for dyslexia showed no significant familiarity preference when listening to a non-native accent. At 26 months, they showed significant native accent familiarity preference for the first time. In fact, both groups showed significant native accent familiarity effects at 26 months, hence in this respect the performance of the at-risk group was similar to the not at-risk infants. These findings suggest that there may be a delay in the development of phonological constancy skills in infants at-risk for dyslexia. Given the developmental sequence of this delay, it is likely (but yet to be shown) that the earlier sensory-based deficits, such as difficulties in encoding amplitude envelope rise times (Kalashnikova et al., 2018) and detecting acoustic information in the speech signal (Guttorm et al., 2005, 2010; Leppänen et al., 2010; Richardson et al., 2003; van Zuijen et al., 2013), may contribute 
PHONOLOGICAL CONSTANCY IN INFANTS AT-RISK FOR DYSLEXIA

to degraded or delayed development of early lexical abilities and a lack of robustness in lexical representations. This, in turn, would interfere with later efficient speech recognition, lexical access, and novel word learning (Swan \& Goswami, 1997).

If it is the case that infants at-risk for dyslexia experience a delay in the development of phonological constancy, it is possible that this skill will emerge once a critical vocabulary size has been attained by these infants, or more advanced linguistic skills have been developed. For instance, a similar trajectory has been observed for vocabulary growth whereby infants at-risk for dyslexia have significantly smaller vocabularies compared to controls around 17-19 months of age (Chen, Wijnen, Koster, \& Schnack, 2017; Koster, Been, \& Diepstra, 2014; van Viersen et al., 2017), but these group differences are no longer consistent after the age of two years (Lyytinen et al., 2004; Scarborough, 1990). Nevertheless, previous evidence suggests that lexical representations in school-aged children with dyslexia continue to lack phonological specificity, as manifested for example in measures of mispronunciation detection, nonword repetition, and paired associate learning (Hulme, Goetz, Gooch, Adams, \& Snowling, 2007; Kalashnikova \& Burnham, 2016; Litt, de Jong, van Bergen, \& Nation, 2013; Litt \& Nation, 2014; Van Alphen et al., 2004). In turn, these under-specified lexical representations are thought to impair the development of phonological awareness and reading skills in at-risk children (Gallagher, Frith, \& Snowling, 2000; Snowling, Gallagher, \& Frith, 2003; Swan \& Goswami, 1997; Torppa, Lyytinen, Erskine, Eklund, \& Lyytinen, 2010).

Two unexpected patterns were also observed in control infants' performance in this study. First, while previous research led us to expect that typically-developing infants at 15- and 19-months would show a preference for familiar words produced in their native accent (Best et al., 2009), this was not the case here. The lack of a robust 
PHONOLOGICAL CONSTANCY IN INFANTS AT-RISK FOR DYSLEXIA

preference at 15-months is not entirely unexpected, since 15-month-olds in the Best et al. (2009) study also failed to look significantly longer to familiar words in their native accent. Regarding the 19-month control data, by inspecting Figure 1 (center panel), it can be seen that infants' looking time for both familiarity conditions in Australian English were higher than for the unfamiliar words in Jamaican English and similar to familiar words in Jamaican English. Thus, typically-developing infants showed a preference for familiar and unfamiliar words in their native accent, while also showing a phonological constancy effect for familiar words in a non-native accent. It is unlikely that infants were familiar with the words from the unfamiliar list as these were specifically selected to be low frequency words not encountered in young children's vocabularies. Instead, it appears that typically-developing children at 19 months like to listen to words produced in their native accent, regardless of whether these words are or are not part of their lexicon; there was recognition of speech of their native variety of English based on general cues such as phonological categories, and stress and phonotactic patterns of the words (Jusczyk, Cutler, \& Redanz, 1993; Jusczyk, Friederici, Wessels, Svenkerud, \& Jusczyk, 1993; Jusczyk \& Luce, 1994). When presented with an unfamiliar accent, they could no longer use these cues to recognise that these words belonged to their native accent, and so they only showed recognition of the highly familiar non-native accent words, thereby exhibiting phonological constancy.

The second interesting but unexpected response pattern was that at 26-months the control infants no longer showed a preference for familiar words produced in Jamaican English. While the at-risk infants also failed to show this preference, this could be expected for the at-risk infants. It was however surprising in the case of the control infants, who did show this preference at 19 months. In fact, as can be seen in Figure 1 (right panel), a slight preference for unfamiliar Jamaican English words 


\section{PHONOLOGICAL CONSTANCY IN INFANTS AT-RISK FOR DYSLEXIA}

emerges for control infants at 26 months. It is possible that this change in preference can be attributed to the aspects of the preferential listening task. Experiments with younger infants have demonstrated that listening preferences can be reversed with age; younger infants tend to show a familiarity preference and older infants a novelty preference (Burnham \& Dodd, 1998; Wetherford \& Cohen, 1973). Therefore, there is a possibility that the developmental change in the direction of control infants' preference is an age-related novelty response. This preferential listening task was chosen to provide an entirely implicit measure of word recognition appropriate for the three ages, but it is possible that preferential listening tasks lose their sensitivity when used with toddlers. In addition to the suitability of the task for this age group, it could be that sample size was a factor. We are unable to fully discard this possibility, but we consider it unlikely given that our sample size was comparable to the sample included in Best et al. (2009), who used an identical task. Further, a post-hoc simulation-based power analysis (Brysbaert \& Stevens, 2018) confirmed that our Linear Mixed Effects models were not underpowered (95.6\% [CI 94.14, 96.79] for the Model - Longitudinal based on 1000 simulations). Nevertheless, these possibilities should be explored in future research with larger samples of infants and measures more commonly used with toddlers (e.g., word identification or novel word learning; van Heugten et al., 2015; Mulak, Best, Tyler, Kitamura, \& Irwin, 2013; Schmale \& Seidl, 2009).

In conclusion, this study provides further evidence that effects of dyslexia can be detected in at-risk children years before they start learning to read and receive a dyslexia diagnosis (Lyytinen et al., 2004; van der Leij et al., 2014). Specifically, we show evidence for phonological constancy in control infants at 19 months of age, but not in infants at family risk for dyslexia at 19 months of age. Given that only a subset of atrisk children later develop dyslexia, it is interesting that their differential performance in 
PHONOLOGICAL CONSTANCY IN INFANTS AT-RISK FOR DYSLEXIA

auditory and language-processing tasks already sets them apart from infants who are not at-risk. Furthermore, it is likely that this effect is not isolated, but relates to deficits found in at-risk and dyslexic children in the domains of native speech perception (Guttorm et al., 2005; 2010; Noordenbos \& Serniclaes, 2015) and lexical acquisition (Chen et al., 2017; Koster et al., 2014). We can conclude that the consolidation of phonological and lexical competence in infants at-risk for dyslexia follows a different developmental pattern from that of their not at-risk peers, which could be due to deficits in phonological or more general auditory-processing skills. This provides further support for the notion that skills not usually associated with reading or spelling may provide useful early indices for risk for dyslexia. 
PHONOLOGICAL CONSTANCY IN INFANTS AT-RISK FOR DYSLEXIA

\section{References}

Bates, D. (2005). Fitting linear mixed models in R. R News, 5(1), 27-30.

Beattie, R. L., \& Manis, F. R. (2015). Rise time perception in children with reading and combined reading and language difficulties. Journal of Learning Disabilities, 46(3), 200-209. https://doi.org/10.1177/0022219412449421

Best, C. T. (1994). The emergence of native-language phonological influences in infants: A perceptual assimilation model. The development of speech perception: The transition from speech sounds to spoken words, 167(224), 233-277.

Best, C. T., Tyler, M. D., Gooding, T. N., Orlando, C. B., \& Quann, C. A. (2009). Development of phonological constancy: Toddlers' perception of native- and Jamaican-accented words. Psychological Science, 20(5), 539-542. https://doi.org/10.1111/j.1467-9280.2009.02327.x

Boada, R., \& Pennington, B. F. (2006). Deficient implicit phonological representations in children with dyslexia. Journal of Experimental Child Psychology, 95(3), 153193.

Bogliotti, C., Serniclaes, W., Messaoud-galusi, S., \& Sprenger-charolles, L. (2008). Discrimination of speech sounds by children with dyslexia: Comparisons with chronological age and reading level controls. Journal of Experimental Child Psychology, 101, 137-155. https://doi.org/10.1016/j.jecp.2008.03.006

Brysbaert, M., \& Stevens, M. (2018). Power analysis and effect size in mixed effects models: a tutorial. Journal of Cognition, 1(1).

Burnham, D., \& Dodd, B. (1998). Familiarity and novelty in infant cross-language studies: Factors, problems, and a possible solution. In C. Rovee-Collier (Ed.), Advances in Infancy Research, 12, 170-187.

Chandrasekaran, B., Hornickel, J., Skoe, E., Nicol, T., Kraus, N. (2009). Context- 


\section{PHONOLOGICAL CONSTANCY IN INFANTS AT-RISK FOR DYSLEXIA}

dependent encoding in the human auditory brainstem relates to hearing speech in noise: Implications for developmental dyslexia. Neuron, 64, 311-319. https://doi.org/10.1016/j.neuron.2009.10.006

Chen, A., Wijnen, F., Koster, C., \& Schnack, H. (2017). Individualized early prediction of familial risk of dyslexia: A study of infant vocabulary development. Frontiers in Psychology, 8(FEB), 1-13. https://doi.org/10.3389/fpsyg.2017.00156

Collet, G., Colin, C., Serniclaes, W., Hoonhorst, I., Markessis, E., Deltenre, P., \& Leybaert, J. (2012). Effect of phonological training in French children with SLI: Perspectives on voicing identification, discrimination and categorical perception. Research in Developmental Disabilities, 33(6), 1805-1818. https://doi.org/10.1016/j.ridd.2012.05.003

Cristia, A., Seidl, A., Vaughn, C., Schmale, R., Bradlow, A., \& Floccia, C. (2012). Linguistic processing of accented speech across the lifespan. Frontiers in Psychology, 3(November), 1-15. https://doi.org/10.3389/fpsyg.2012.00479

Curtin, S., Byers-heinlein, K., \& Werker, J. F. (2011). Bilingual beginnings as a lens for theory development : PRIMIR in focus. Journal of Phonetics, 39(4), 492-504. https://doi.org/10.1016/j.wocn.2010.12.002

Di Liberto, G. M., Peter, V., Kalashnikova, M., Goswami, U., Burnham, D., \& Lalor, E. C. (2018). Atypical cortical entrainment to speech in the right hemisphere underpins phonemic deficits in dyslexia. Neuroimage, 175, 70-79.

Doelling, K.B., Arnal, L.H., Ghitza, O., \& Poeppel, D. (2014) Acoustic landmarks drive delta-theta oscillations to enable speech comprehension by facilitating perceptual parsing. Neuroimage, $85,761-768$. https:// doi:

10.1016/j.neuroimage.2013.06.035 


\section{PHONOLOGICAL CONSTANCY IN INFANTS AT-RISK FOR DYSLEXIA}

Fenson, L., Dale, P. S., Reznick, J. S., Bates, E., Thal, D. J., Pethick, S. J., ... \& Stiles, J. (1994). Variability in early communicative development. Monographs of the society for Research in Child Development, i-185.

Fisher, S. E., \& DeFries, J. C. (2002). Developmental dyslexia: genetic dissection of a complex cognitive trait. Nature Reviews Neuroscience, 3(10), 767-780. https://doi.org/10.1038/nrn936

Gallagher, A., Frith, U., \& Snowling, M. J. (2000). Precursors of literacy delay among children at genetic risk of dyslexia. Journal of Child Psychology and Psychiatry, and Allied Disciplines, 41(2), 203-213.

https://doi.org/10.1017/S0021963099005284

Gogate, L. J. (2010). Learning of syllable-object relations by preverbal infants: The role of temporal synchrony and syllable distinctiveness. Journal of Experimental Child Psychology, 105(3), 178-197.

Goswami, U. (2011). A temporal sampling framework for developmental dyslexia.

Trends in Cognitive Sciences, 15(1), 3-10.

https://doi.org/10.1016/j.tics.2010.10.001

Goswami, U. (2015). Sensory theories of developmental dyslexia: three challenges for research. Nature Reviews Neuroscience, 16(1), 43-54.

https://doi.org/10.1038/nrn3836

Goswami, U. (2018). A neural basis for phonological awareness? An oscillatory temporal-sampling perspective. Current Directions in Psychological Science, 27(1), 56-63.

Goswami, U., Fosker, T., Huss, M., Mead, N., \& Szucs, D. (2011). Rise time and formant transition duration in the discrimination of speech sounds: the Ba-Wa distinction in developmental dyslexia. Developmental Science, 14(1), 34-43. 


\section{PHONOLOGICAL CONSTANCY IN INFANTS AT-RISK FOR DYSLEXIA}

https://doi.org/10.1111/j.1467-7687.2010.00955.x

Goswami, U., Thomson, J., Richardson, U., Stainthorp, R., Hughes, D., Rosen, S., \& Scott, S. K. (2002). Amplitude envelope onsets and developmental dyslexia: A new hypothesis. Proceedings of the National Academy of Sciences of the United States of America, 99(16), 10911-10916. https://doi.org/10.1073/pnas.122368599

Goswami, U., Wang, H.-L. S., Cruz, A., Fosker, T., Mead, N., \& Huss, M. (2011). Language-universal sensory deficits in developmental dyslexia: English, Spanish, and Chinese. Journal of Cognitive Neuroscience, 23(2), 325-337. https://doi.org/10.1162/jocn.2010.21453

Guttorm, T. K., Leppänen, P. H. T., Hamalainen, J. A., Eklund, K. M., \& Lyytinen, H. J. (2010). Newborn event-related potentials predict poorer pre-reading skills in children at risk for dyslexia. Journal of Learning Disabilities, 43(5), 391-401. https://doi.org/10.1177/0022219409345005

Guttorm, T. K., Leppänen, P. H. T., Poikkeus, A.-M., Eklund, K. M., Lyytinen, P., \& Lyytinen, H. J. (2005). Brain event-related potentials (ERPs) measured at birth predict later language development in children with and without familial risk for dyslexia. Cortex, 41(3), 291-303. https://doi.org/10.1016/S0010-9452(08)70267-3

Hamalainen, J.A., Leppanen, P.H.T., Guttorm, T.K., \& Lyytinen, H. (2008). Eventrelated potentials to pitch and rise time change in children with reading disabilities and typically-reading children. Clinical Neurophysiology, 119 (1), 100-15. https://doi.org/10.1016/j.clinph.2007.09.064

Hamalainen, J. A., Salminen, H. K., \& Leppänen, P. H. T. (2013). Basic auditory processing deficits in dyslexia: Systematic review of the behavioral and eventrelated potential/ field evidence. Journal of Learning Disabilities, 46(5), 413-427. https://doi.org/10.1177/0022219411436213 
PHONOLOGICAL CONSTANCY IN INFANTS AT-RISK FOR DYSLEXIA

Hulme, C., Goetz, K., Gooch, D., Adams, J., \& Snowling, M. J. (2007). Paired-associate learning, phoneme awareness, and learning to read. Journal of Experimental Child Psychology, 96(2), 150-166. https://doi.org/10.1016/j.jecp.2006.09.002

Jusczyk, P. W., Cutler, A., \& Redanz, N. (1993). Infants' Preference for the Predominant Stress Patterns of English Words. Child Development, 64(3), 675687. Retrieved from

http://www.jstor.org/stable/1131210?seq=1\#page_scan_tab_contents

Jusczyk, P. W., Friederici, A. D., Wessels, J. M. I., Svenkerud, V. Y., \& Jusczyk, A. M. (1993). Infants' Sensitivity to the Sound Patterns of Native Language Words.

Journal of Memory and Language, 32(3), 402-420.

https://doi.org/10.1006/jmla.1993.1022

Jusczyk, P. W., \& Luce, P. A. (1994). Infants' Sensitivity to Phonotactic Patterns in the Native Language. Journal of Memory and Language, 33(5), 630-645.

https://doi.org/10.1006/jmla.1994.1030

Kalashnikova, M., \& Burnham, D. (2016). Novel Word Learning, Reading Difficulties, and Phonological Processing Skills. Dyslexia, 22(2), 101-119.

https://doi.org/10.1002/dys.1525

Kalashnikova, M., Goswami, U., \& Burnham, D. (2018). Mothers speak differently to infants at-risk for dyslexia. Developmental Science, 21(1), 1-15.

https://doi.org/10.1111/desc.12487

Koster, C., Been, P. H., \& Diepstra, H. D. (2014). Differences at 17 Months :

Productive Familial Risk for Dyslexia and. Journal of Speech Language and Hearing Research, 48(April 2005), 426-438.

Kuznetsova, A., Brockhoff, P. B., \& Christensen, R. H. B. (2015). Package "lmerTest." R Package Version, 2(0). 


\section{PHONOLOGICAL CONSTANCY IN INFANTS AT-RISK FOR DYSLEXIA}

Kuhl, P. K. (2004). Early language acquisition: cracking the speech code. Nature Reviews Neuroscience, 5(11), 831-843. https://doi.org/10.1038/nrn1533

Law, J.M., Wouters, J. \& Ghesquiere, P. (2017). The influences and outcomes of phonological awareness: a study of MA, PA and auditory processing in prereaders with a family risk of dyslexia. Developmental Science, 20: e12453.

Lehongre, K., Ramus, F., Villiermet, N., Schwartz, D., \& Giraud, A. L. (2011). Altered low-gamma sampling in auditory cortex accounts for the three main facets of dyslexia. Neuron, 72, 1080-1090. https://doi.org/10.1016/j.neuron.2011.11.002

Leppänen, P. H. T., Hämäläinen, J. A., Salminen, H. K., Eklund, K. M., Guttorm, T. K., Lohvansuu, K., ... Lyytinen, H. J. (2010). Newborn brain event-related potentials revealing atypical processing of sound frequency and the subsequent association with later literacy skills in children with familial dyslexia. Cortex, 46(10), 13621376. https://doi.org/10.1016/j.cortex.2010.06.003

Litt, R. A., de Jong, P. F., van Bergen, E., \& Nation, K. (2013). Dissociating crossmodal and verbal demands in paired associate learning (PAL): What drives the PALreading relationship? Journal of Experimental Child Psychology, 115(1), 137-149. https://doi.org/10.1016/j.jecp.2012.11.012

Litt, R. A., \& Nation, K. (2014). The nature and specificity of paired associate learning deficits in children with dyslexia. Journal of Memory and Language, 71(1), 71-88. https://doi.org/10.1016/j.jml.2013.10.005

Lyytinen, H., Aro, M., Eklund, K., Erskine, J., Guttorm, T., Laakso, M.-L., ... Torppa, M. (2004). The development of children at familial risk for dyslexia: birth to early school age. Annals of Dyslexia, 54(2), 184-220. https://doi.org/10.1007/s11881004-0010-3

Mattock, K., Molnar, M., Polka, L., \& Burnham, D. (2008). The developmental course 
PHONOLOGICAL CONSTANCY IN INFANTS AT-RISK FOR DYSLEXIA

of lexical tone perception in the first year of life. Cognition, 106(3), 1367-1381. https://doi.org/10.1016/j.cognition.2007.07.002

Moll, K., Loff, A., \& Snowling, M. J. (2013). Cognitive Endophenotypes of Dyslexia. Scientific Studies of Reading (March), 1-13. https://doi.org/10.1080/10888438.2012.736439

Mulak, K. E., Best, C. T., Tyler, M. D., Kitamura, C., \& Irwin, J. R. (2013). Development of phonological constancy : 19-month-olds , but not 15-month-olds , identify words in a non-native regional accent. Child Development, 84(6), 20642078. https://doi.org/10.1111/cdev.12087

Nazzi, T., \& Bertoncini, J. (2003). Before and after the vocabulary spurt : two modes of word acquisition? Developmental Science, 2, 136-142.

Noordenbos, M. W., Segers, E., Serniclaes, W., Mitterer, H., \& Verhoeven, L. (2012). Allophonic mode of speech perception in Dutch children at risk for dyslexia: A longitudinal study. Research in Developmental Disabilities, 33(5), 1469-1483. https://doi.org/10.1016/j.ridd.2012.03.021

Noordenbos, M. W., \& Serniclaes, W. (2015). The Categorical Perception Deficit in Dyslexia: A Meta-Analysis The Categorical Perception Deficit in Dyslexia. Scientific Studies of Reading, 19(5), 340-359. https://doi.org/10.1080/10888438.2015.1052455

Patrick, P. L. (1999). Urban Jamaican Creole: Variation in the mesolect. John Benjamins Publishing.

Pennington, B. F., \& Lefly, D. L. (2001). Early reading development in children at family risk for dyslexia. Child Development, 72(3), 816-833. https://doi.org/10.1111/1467-8624.00317

Plakas, A., van Zuijen, T. L., van Leeuwen, T., Thomson, J. M., \& van der Leij, A. 
PHONOLOGICAL CONSTANCY IN INFANTS AT-RISK FOR DYSLEXIA

(2013). Impaired non-speech auditory processing at a pre-reading age is a riskfactor for dyslexia but not a predictor: An ERP study. Cortex, 49(4), 1034-1045. https://doi.org/10.1016/j.cortex.2012.02.013

Poelmans, H., Luts, H., Vandermosten, M., Boets, B., Ghesquiere, P. \& Wouters, J. (2011). Reduced sensitivity to slow-rate dynamic auditory information in children with dyslexia. Research in Developmental Disabilities, 32 (6), 2810-19. http://dx.doi.org/10.1016/j.ridd.2017.09.005

Power, A. J., Mead, N., Barnes, L., \& Goswami, U. (2012). Neural Entrainment to Rhythmically Presented Auditory, Visual, and Audio-Visual Speech in Children. Frontiers in Psychology, 3, 1-13. https://doi.org/10.3389/fpsyg.2012.00216

Power, A. J., Mead, N., Barnes, L., \& Goswami, U. (2013). Neural entrainment to rhythmic speech in children with dyslexia. Frontiers in Human Neuroscience, 7, 777. https://doi.org/10.3389/fnhum.2013.00777

Ramus, F. (2003). Theories of developmental dyslexia: insights from a multiple case study of dyslexic adults. Brain, 126(4), 841-865. https://doi.org/10.1093/brain/awg076

Ramus, F., Marshall, C. R., Rosen, S., \& Van Der Lely, H. K. J. (2013). Phonological deficits in specific language impairment and developmental dyslexia: Towards a multidimensional model. Brain, 136(2), 630-645.

https://doi.org/10.1093/brain/aws356

Richardson, U., Leppänen, P. H. T., Leiwo, M., \& Lyytinen, H. J. (2003). Speech perception of infants with high familial risk for dyslexia differ at the age of 6 months. Developmental Neuropsychology, 23(3), 385-397. https://doi.org/10.1207/S15326942DN2303_5 
PHONOLOGICAL CONSTANCY IN INFANTS AT-RISK FOR DYSLEXIA

Scarborough, H. S. (1990). Very early language deficits in dyslexic children. Child Development, 61(6), 1728-1743.

Schmale, R., Cristia, A., \& Seidl, A. (2012). Toddlers recognize words in an unfamiliar accent after brief exposure. Developmental Science, 6, 732-738.

https://doi.org/10.1111/j.1467-7687.2012.01175.x

Schmale, R., Cristia, A., Seidl, A., \& Johnson, E. K. (2010). Developmental Changes in Infants’ Ability to Cope with Dialect Variation in Word Recognition. Infancy, 15(6), 650-662. https://doi.org/10.1111/j.1532-7078.2010.00032.x

Schmale, R., \& Seidl, A. (2009). Accommodating variability in voice and foreign accent : flexibility of early word representations. Developmental Science, 4, 583601. https://doi.org/10.1111/j.1467-7687.2009.00809.x

Shannon, R.V., Zeng, F.G., Kamath, V., Wygonski, J., \& Ekelid, M. (1995). Speech recognition with primarily temporal cues. Science, 270 (5234), 303-4. https://doi.org/10.1126/science.270.5234.303

Snowling, M.J. (2000). Dyslexia. Oxford: Blackwell Publishers.

Snowling, M. J., Gallagher, A., \& Frith, U. (2003). Family risk of dyslexia is continuous: individual differences in the precursors of reading skill. Child Development, 74(2), 358-373. https://doi.org/10.1111/1467-8624.7402003

Snowling, M. J., \& Melby-Lervag, M. (2016). Oral language deficits in familial dyslexia: a meta-analysis and review. Psychological Bulletin, 142(5), 448.

Soleimani, F., \& Azari,N. (2014). Bayley scales of infant and toddler development, (Bayley-III).

Stager, C. L., \& Werker, J. F. (1997). Infants listen for more phonetic detail in speech perception than in word-learning tasks. Nature, 388(6640), 381-382. https://doi.org/10.1038/41102 


\section{PHONOLOGICAL CONSTANCY IN INFANTS AT-RISK FOR DYSLEXIA}

Stefanics, G., Fosker, T., Huss, M., Mead, N., Szucs, D., \& Goswami, U. (2011). Auditory sensory deficits in developmental dyslexia: A longitudinal ERP study. Neuroimage, 57(3), 723-732. https://doi.org/10.1016/j.neuroimage.2011.04.005

Surányi, Z., Csépe, V., Richardson, U., Thomson, J.M., Honbolygó, F., \& Goswami, U. (2009). Sensitivity to rhythmic parameters in dyslexic children: A comparison of Hungarian and English. Reading \& Writing, 22, 1,41-56.

Swan, D., \& Goswami, U. (1997). Picture naming deficits in developmental dyslexia: The phonological representations hypothesis. Brain and Language, 56, 334-353. https://doi.org/10.1111/1467-7687.00054

Swingley, D. (2005). 11-month-olds' knowledge of how familiar words sound. Developmental Science, 8, 432-443. https://doi.org/10.1111/j.14677687.2005.00432.x

Swingley, D., \& Aslin, R. N. (2000). Spoken word recognition and lexical representation in very young children. Cognition, 76(2), 147-166. https://doi.org/10.1016/S0010-0277(00)00081-0

Swingley, D., \& Aslin, R. N. (2007). Lexical competition in young children's word learning. Cognitive Psychology, 54(2), 99-132. https://doi.org/10.1016/j.cogpsych.2006.05.001

Tsuji, S., \& Cristia, A. (2014). Perceptual attunement in vowels: A meta-analysis. Developmental Psychobiology, 56(2), 179-191. https://doi.org/10.1002/dev.21179 Van Alphen, P., Bree, E. De, Gerrits, E., Jong, J. De, Wilsenach, C., \& Wijnen, F. (2004). Early Language Development in Children with a Genetic Risk of Dyslexia. Dyslexia, 10, 265-288. https://doi.org/10.1002/dys.272

Van Bergen, E., De Jong, P. F., Regtvoort, A., Oort, F., Van Otterloo, S., \& Van Der Leij, A. (2011). Dutch children at family risk of dyslexia: Precursors, reading 
PHONOLOGICAL CONSTANCY IN INFANTS AT-RISK FOR DYSLEXIA

development, and parental effects. Dyslexia, 17(1), 2-18.

https://doi.org/10.1002/dys.423

Van Der Leij, A., Van Bergen, E., Van Zuijen, T., De Jong, P., Maurits, N., \& Maassen, B. (2013). Precursors of developmental dyslexia: An overview of the longitudinal dutch dyslexia programme study. Dyslexia, 19(4), 191-213.

Van Heugten, M., Krieger, D. R., \& Johnson, E. K. (2015). The Developmental Trajectory of Toddlers' Comprehension of Unfamiliar Regional Accents. Language Learning and Development, 11(1), 41-65. https://doi.org/10.1080/15475441.2013.879636

van Viersen, S., de Bree, E. H., Verdam, M., Krikhaar, E., Maassen, B., van der Leij, A., \& de Jong, P. F. (2017). Delayed early vocabulary development in children at family risk of dyslexia. Journal of Speech, Language, and Hearing Research, 60(4), 937-949.

Van Zuijen, T. L., Plakas, A., Maassen, B. A. M., Maurits, N. M., \& van der Leij, A. (2013). Infant ERPs separate children at risk of dyslexia who become good readers from those who become poor readers. Developmental Science, 16(4), 554563. https://doi.org/10.1111/desc. 12049

Wassink, A. B. (2006). A geometric representation of spectral and temporal vowel features: Quantification of vowel overlap in three linguistic varieties. The Journal of the Acoustical Society of America, 119(4), 2334-2350.

Werker, J. F., \& Curtin, S. A. (2005). PRIMIR: A developmental framework of infant speech processing. Language Learning and Development, 1(2), 197-234.

Werker, J. F., \& Hensch, T. K. (2015). Critical periods in speech perception : New directions. Annual Review of Psychology, 66, 173-196. https://doi.org/10.1146/annurev-psych-010814-015104 
PHONOLOGICAL CONSTANCY IN INFANTS AT-RISK FOR DYSLEXIA

Werker, J. F., \& Tees, R. C. (2005). Speech perception as a window for understanding plasticity and commitment in language systems of the brain. Developmental Psychobiology, 46(3), 233-251.

Wetherford, M. J., \& Cohen, L. B. (1973). Developmental changes in infant visual preferences for novelty and familiarity. Child Development, 416-424.

Yoshida, K. A., Fennell, C. T., Swingley, D., \& Werker, J. F. (2009). Fourteen-monthold infants learn similar-sounding words. Developmental Science, 12(3), 412-418. https://doi.org/10.1111/j.1467-7687.2008.00789.x

Ziegler, J. C., \& Goswami, U. (2005). Reading acquisition, developmental dyslexia, and skilled reading across languages: A psycholinguistic grain size theory. Psychological Bulletin, 131(1), 3-29. https://doi.org/10.1037/0033-2909.131.1.3

Zoccolotti, P., \& Friedmann, N. (2010). From dyslexia to dyslexias, from dysgraphia to dysgraphias, from a cause to causes: A look at current research on developmental dyslexia and dysgraphia. Cortex, 46(10), 1211-1215.

https://doi.org/10.1016/j.cortex.2010.09.003 


\section{Appendix A}

Stimuli words used in the familiar and the unfamiliar conditions of the listening preference task.

\begin{tabular}{rll}
\hline & Familiar & Unfamiliar \\
\hline 1 & ball & ash \\
2 & bear & baker \\
3 & bike & boaster \\
4 & birdy & bribe \\
5 & cat & brute \\
6 & doggy & copy \\
7 & hair & gawk \\
8 & paper & lair \\
9 & spoon & moonstruck \\
10 & stroller & nibble \\
11 & flower & turkey \\
12 & mouth & boughs \\
13 & tickle & cobble \\
14 & apple & doubter \\
15 & baby & flight \\
16 & bathtub & hearthrug \\
17 & boat & lore \\
18 & bottle & mares \\
19 & button & toad \\
20 & car & toughen \\
21 & door & vase \\
22 & eyes & weighty \\
23 & keys & wreath \\
24 & toothbrush & dabble \\
\hline & & \\
\hline
\end{tabular}


PHONOLOGICAL CONSTANCY IN INFANTS AT-RISK FOR DYSLEXIA

\section{Appendix B}

Table 1. Linear mixed effect Model 1 results $(N=43)$.

\begin{tabular}{|c|c|c|c|}
\hline & Estimate & SE & $\mathrm{t}$ \\
\hline (Intercept) & 8.399 & 0.992 & 8.464 \\
\hline Group(NAR) & -0.572 & 1.387 & -0.412 \\
\hline Accent $(J E)$ & -0.628 & 1.089 & -0.576 \\
\hline Familiarity(Familiar) & -0.727 & 1.182 & -0.616 \\
\hline Age(19) & -1.246 & 1.156 & -1.078 \\
\hline Age(26) & 0.809 & 1.069 & 0.757 \\
\hline Group(NAR):Accent(JE) & 0.046 & 1.521 & 0.030 \\
\hline Group(NAR):Familiarity(Familiar) & 2.059 & 1.653 & 1.246 \\
\hline Accent(JE):Familiarity(Familiar) & 1.463 & 1.541 & 0.949 \\
\hline Group(NAR):Age(19) & 3.225 & 1.638 & 1.969 \\
\hline Group(NAR):Age(26) & 1.069 & 1.531 & 0.698 \\
\hline $\operatorname{Accent}(J E): \operatorname{Age}(19)$ & 0.109 & 1.502 & 0.072 \\
\hline $\operatorname{Accent}(J E): \operatorname{Age}(26)$ & 0.843 & 1.507 & 0.559 \\
\hline Familiarity(Familiar):Age(19) & 2.399 & 1.744 & 1.376 \\
\hline Familiarity(Familiar):Age(26) & 3.371 & 1.519 & 2.219 \\
\hline Group(NAR):Accent(JE):Familiarity(Familiar) & -1.727 & 2.151 & -0.803 \\
\hline Group(NAR):Accent(JE):Age(19) & -2.142 & 2.123 & -1.009 \\
\hline Group(NAR):Accent(JE):Age(26) & -0.929 & 2.141 & -0.434 \\
\hline Group(NAR):Familiarity(Familiar):Age(19) & -4.329 & 2.468 & -1.754 \\
\hline Group(NAR):Familiarity(Familiar):Age(26) & -3.945 & 2.168 & -1.82 \\
\hline Accent(JE):Familiarity(Familiar):Age(19) & -2.313 & 2.125 & -1.089 \\
\hline Accent(JE):Familiarity(Familiar):Age(26) & -4.939 & 2.131 & -2.318 \\
\hline $\begin{array}{l}\text { Group(NAR):Accent(JE):Familiarity(Familiar):Age( } \\
\text { 19) }\end{array}$ & 5.718 & 3.002 & 1.904 \\
\hline $\begin{array}{l}\text { Group(NAR):Accent(JE):Familiarity(Familiar):Age( } \\
\text { 26) }\end{array}$ & 2.601 & 3.028 & 0.859 \\
\hline
\end{tabular}

Table 2. Parameters and summary of the linear mixed effect Model 2 analysing ARDx and CTR infants' performance at 15 months $(N=35)$.

\begin{tabular}{lrrr}
\hline & Estimate & SE & \multicolumn{1}{c}{$\mathrm{t}$} \\
\hline (Intercept) & 7.964 & 0.974 & 7.964 \\
Accent(JE) & -0.628 & 0.957 & -0.628
\end{tabular}


PHONOLOGICAL CONSTANCY IN INFANTS AT-RISK FOR DYSLEXIA

Familiarity(Familiar)

Group(NAR)

Accent(JE):Familiarity(Familiar)

Accent(JE):Group(NAR)

Familiarity(Familiar):Group(NAR)

Accent(JE):Familiarity(Familiar):Group(NAR)

\begin{tabular}{rrr}
-0.801 & 1.077 & -0.801 \\
-0.377 & 1.359 & -0.378 \\
1.463 & 1.353 & 1.463 \\
0.046 & 1.335 & 0.0462 \\
2.132 & 1.503 & 2.132 \\
-1.727 & 1.888 & -1.727 \\
\hline
\end{tabular}

Table 3. Parameters and summary of the linear mixed effect Model 3 analysing ARDx and CTR infants' performance at 19 months $(N=35)$.

\begin{tabular}{lrrr}
\hline & Estimate & \multicolumn{2}{l}{ SE } \\
\hline (Intercept) & 6.919 & 0.947 & 6.919 \\
Accent(JE) & -0.519 & 0.954 & -0.519 \\
Familiarity(Familiar) & 1.876 & 1.123 & 1.876 \\
Group(NAR) & 2.997 & 1.357 & 2.997 \\
Accent(JE):Familiarity(Familiar) & -0.849 & 1.349 & -0.849 \\
Accent(JE):Group(NAR) & -2.096 & 1.366 & -2.096 \\
Familiarity(Familiar):Group(NAR) & -2.651 & 1.609 & -2.651 \\
Accent(JE):Familiarity(Familiar):Group(NAR) & 3.991 & 1.932 & 3.991 \\
\hline
\end{tabular}

Table 4. Parameters and summary of the linear mixed effect Model 4 analysing ARDx and CTR infants' performance at 26 months $(N=37)$.

\begin{tabular}{lrrr}
\hline & Estimate & SE & \multicolumn{1}{c}{$\mathrm{t}$} \\
\hline (Intercept) & 9.251 & 1.139 & 8.118 \\
Accent(JE) & 0.115 & 1.171 & 0.098 \\
Familiarity(Familiar) & 2.624 & 1.156 & 2.271 \\
Group(NAR) & 0.734 & 1.664 & 0.441 \\
Accent(JE):Familiarity(Familiar) & -3.507 & 1.641 & -2.137 \\
Accent(JE):Group(NAR) & -0.782 & 1.691 & -0.462 \\
Familiarity(Familiar):Group(NAR) & -1.845 & 1.699 & -1.086 \\
Accent(JE):Familiarity(Familiar):Group(NAR) & 0.904 & 2.381 & 0.380 \\
\hline
\end{tabular}

